\section{Potential benefit of rotational radiation therapy}

\author{
Jason Vickress', Michael Lock ${ }^{1,2,3}$, Simon Lo 4 Slav Yartsev*,1,2,3
}

First draft submitted: 7 December 2016; Accepted for publication: 14 December 2016; Published online: 9 January 2017

In our recent article published in Future Oncology [1], we reported the outcomes of radiation therapy administered to 195 liver cancer patients. In addition to traditional patient specific parameters, such as age, sex, Child-Pugh (CP) class [2], we included dosimetric data. To our surprise, the volume of normal liver receiving more than $24 \mathrm{~Gy}$ (V24) correlated positively with diseasefree survival for rotational modalities of radiation delivery (volumetric-modulated arc therapy and TomoTherapy), but not for the patients treated with fixed-beams intensity-modulated radiation therapy. This finding indicates that relatively large doses delivered in the area adjacent to the tumor in an isotropic manner are able to eradicate microscopic spread of malignant cells, while fixed-beam delivery misses these cells in the regions between the beams.

In radiation therapy literature, the main focus is on motion and margins $[3,4]$. The clinical tumor volume created to account for all microscopic spread has not been established for secondary and primary liver disease. Indeed, in many studies, a margin for clinical tumor volume is not added based on the assumption that microscopic disease is of minor importance in this disease site. This is at odds with surgical data where margin beyond the gross tumor has been shown to be independently associated with overall survival $[5,6]$.
Another reason for limiting margins is that with more encompassing treatment, there is an increased risk of radiationinduced liver disease (RILD). Indeed, landmark work by the Michigan group on whole liver radiation plus a boost resulted in significant RILD [7]. This concern for RILD has led to the modern management philosophy to use stereotactic body radiation therapy to focus on the gross disease. This has allowed very safe dose escalation using partial volume tolerance data. The effect of low-dose spillage was shown to be dependent on patient characteristics: CP class A patients were not affected, while $\mathrm{CP}$ class $\mathrm{B}$ patients experiencing grade III/IV liver toxicity had significantly higher mean liver dose, higher dose to a-third normal liver, and larger volumes of liver receiving doses $<2.5-15$ Gy in 2.5-Gy increments [8]. Therefore, emphasizing avoidance of low dose spillage may not be necessary in patients with certain known parameters, especially in the absence of liver parenchymal disease.

We hypothesize that the density of neoplastic cells is decreasing gradually with distance from the gross tumor. The lower is the density of malignant cells, the better is their oxygenation The density of cancerous cells is so low further from the tumor that the patient's immune system or targeted chemotherapy [9] can eliminate residual disease. However, one may need to

\section{KEYWORDS}

- hepatocellular carcinoma

- radiotherapy • stereotactic body radiation therapy $\bullet$ treatment outcomes 
add radiation to eradicate cancer spread in the area closer to the tumor to result in a diseasefree survival advantage. Ideally, the planned dose should gradually decrease around the tumor in order to match the diminishing density of neoplastic cells. There are several options for testing this hypothesis: imaging of low-density cancerous cells could be possible with rapidly advancing technology [10-13]; computer modeling of cell distribution around the tumor [14]; and clinical trials that include prescription dose to the planning target volume and controlled $>24$ Gy dose spillage around the gross tumor volume. This differs from a trend in stereotactic body radiation therapy where the goal is to provide a sharp drop-off of dose by prescribing to a lower isodose line or to use particle beam therapy with a sharp Bragg peak. Our finding is intriguing, even though it may be a spurious statistical anomaly, warranting validation in other databases. If our hypothesis can be validated, it would prompt a reversal of current trends in management philosophy.

\section{Financial \& competing interests disclosure}

The authors have no relevant affiliations or financial involvement with any organization or entity with a financial interest in or financial conflict with the subject matter or materials discussed in the manuscript. This includes employment, consultancies, honoraria, stock ownership or options, expert testimony, grants or patents received or pending, or royalties.

No writing assistance was utilized in the production of this manuscript.

\section{References}

1 Vickress J, Lock M, Lo S et al. A multivariable model to predict survival for patients with hepatic carcinoma or liver metastasis receiving radiotherapy. Future Oncol. 13(1), 19-30 (2017).

2 Hirokawa F, Hayashi M, Miyamoto Y et al. Predictors of poor prognosis by recurrence patterns after curative hepatectomy for hepatocellular carcinoma in Child-Pugh classification A. Hepatogastroenterology 62(137), 164-168 (2015).

3 Yartsev S, Bauman G. Target margins in radiotherapy of prostate cancer. $\mathrm{Br}$. J. Radiol. 89(1067), 20160312 (2016).

4 Kuo HC, Liu WS, Wu A et al. Influence of resection margin on survival in hepatic resections for colorectal liver metastases. Radiat. Oncol. 5, 48 (2010).

5 Sadot E, Groot Koerkamp B, Leal JN et al. Resection margin and survival in 2368 patients undergoing hepaticresection for metastatic colorectal cancer: surgical technique or biologic surrogate? Ann. Surg. 262 (3), 476-485; discussion 483-485 (2015).

6 Vandeweyer D, Neo EL, Chen JW, Maddern GJ, Wilson TG, Padbury RT. Influence of resection margin on survival in hepatic resections for colorectal liver metastases. $H P B$ (Oxford) 11(6), 499-504 (2009).

7 Lawrence TS, Robertson JM, Anscher MS, Jirtle RL, Ensminger WD, Fajardo LF. Hepatic toxicity resulting from cancer treatment. Int. J. Radiat. Oncol. Biol. Phys. 31(5), 1237-1248 (1995).

8 Lasley FD, Mannina EM, Johnson CS et al. Treatment variables related to liver toxicity in patients with hepatocellular carcinoma, Child-Pugh class A and B enrolled in a Phase $1-11$ trial of stereotactic body radiation therapy. Pract. Radiat. Oncol. 5(5), e443-e449 (2015).

9 Qian Y, Zeng ZC, Ji Y, Xiao YP. Microinvasion of liver metastases from colorectal cancer: predictive factors and application for determining clinical target volume. Radiat. Oncol. 10, 125 (2015).
10 Haldorsen IS, Popa M, Fonnes T et al. Multimodal imaging of orthotopic mouse model of endometrial carcinoma. PLoS ONE 10(8), e0135220 (2015).

11 Harmsen S, Huang R, Wall MA et al. Surface-enhanced resonance Raman scattering nanostars for high-precision cancer imaging. Sci. Transl. Med. 7(271), 271ra7 (2015).

12 Ji M, Lewis S, Camelo-Piragua S et al. Detection of human brain tumor infiltration with quantitative stimulated Raman scattering microscopy. Sci. Transl. Med. 7(309), 309ra163 (2015).

13 Sudo H, Tsuji AB, Sugyo A et al. Establishment and evaluation of a new highly metastatic tumor cell line 5a-D-Luc-ZsGreen expressing both luciferase and green fluorescent protein. Int. J. Oncol. 48(2), 525-532 (2016).

14 Engwer C, Knappitsch M, Surulescu C. A multiscale model for glioma spread including cell-tissue interactions and proliferation. Math. Biosci. Eng. 13(2), 443-460 (2016). 